\title{
DIAGNÓSTICO EM ANAPLASMOSE BOVINA
}

\author{
DIAGNOSIS IN BOVINE ANAPLASMOSIS
}

Odilon Vidotto $^{1}$ Elizabete Regina Marangoni Marana ${ }^{2}$

\section{- REVISÃO BIBLIOGRÁFICA -}

RESUMO

\begin{abstract}
Anaplasma marginale (THEILER 1910) é uma rickettsia intra-eritrocitária obrigatória de ruminantes susceptíveis, transmitida biológica e mecanicamente por carrapatos e insetos hematófagos. Ela determina o aparecimento de formas clínicas aguda, superaguda, leve elou crônica, com um período pré-patente de 20 a 40 dias seguido por parasitemia e intensa anemia, provocando perdas com um custo estimado de 40 milhões de dólares anuais; está amplamente distribuída nas regiões tropicais, subtropicais e temperadas do mundo. A. marginale confere imunidade de origem humoral e celular que não é dependente de infecção persistente. O diagnóstico é baseado em sinais clínicos, detecção do microrganismo no sangue, anticorpos no soro ou alterações patológicas post mortem. O objetivo deste trabalho é reunir informações sobre aspectos de diagnóstico da anaplasmose bovina.
\end{abstract}

Palavras-chave: Anaplasma marginale, bovino, prevalência, imunidade, diagnóstico.

\section{SUMMARY}

Anaplasma marginale (THEILER, 1910), a rickettsial hemoparasite of ruminants, is transmited biologically and mecanically by ticks and haematofagous insects. It has a prepatent period of 20 to 40 days, followed by high parasitemia and severe anemia. Infected animals can develop a mild, aguda, hiperaguda or cronic clinical forms of the disease. A. marginale has an worldwide distribuition with high incidence in tropical and subtropical regions. A. marginale promove an immunity not dependent of a persistent infection, involving both, humural and celular immunological mechanisms. Diagnosis is based on clinical signs, detection of the microrganisms on the blood, antibodies on the serum or post-mortem pathological changes. Informations about the diagnostic aspects of anaplasmosis are reviewed.
Key words: Anaplasma marginale, prevalence, immunity, diagnostics.

\section{INTRODUÇÃO}

Anaplasmose bovina é uma infecção causada por Anaplasma marginale (THEILER, 1910) e A. centrale (THEILER, 1911), rickettsias da família Anaplasmataceae, ordem Rickettsiales (RISTIC \& KREIER, 1974). A espécie mais patogênica e de maior importância para bovinos é o $\boldsymbol{A}$. marginale. Essa rickettsia apresenta-se como corpúsculos intraeritrocitários, visualizados em microscopia óptica como pequenos pontos escuros, de localização periférica, variando entre $0,1 \mu \mathrm{m}$ a $0,8 \mu \mathrm{m}$ (FARIAS, 1995).

O A. marginale está amplamente distribuído nas regiões tropicais, subtropicais e temperadas do mundo (PALMER, 1989). Está presente na América do Norte, América Central, América do Sul, Austrália e Sudeste Africano (JAMES et al., 1985; DALGLIESH $\boldsymbol{e t}$ al., 1990), sendo endêmica no México, América Central, região Caribeana das Américas, Guianas, Venezuela e Colômbia (JAMES et al., 1985). A prevalência varia de $2,1 \%$ a $100 \%$ (PATARROYO $\boldsymbol{e t}$ al., 1978; BAUMGARTNER $\boldsymbol{e t}$ al., 1992; JONGEJAN $\boldsymbol{e t}$ al., 1988; JORGENSEN $\boldsymbol{e}$ t al., 1992). No Brasil, a prevalência da anaplasmose também tem uma grande variação, com índices de 12,3 a 100\% (RIBEIRO \& REIS, 1981; OLIVEIRA

\footnotetext{
${ }^{1}$ Professor do Departamento de Medicina Veterinária Preventiva, Universidade Estadual de Londrina (UEL), CP 6001, 86051-970, Londrina, PR. E-mail: vidotto@uel.br, Fax 0433714714. Autor para correspondência

${ }^{2}$ Médico Veterinário do Departamento de Medicina Veterinária Preventiva, UEL. 
et al., 1992; MADRUGA et al., 1994; ARTILES $\boldsymbol{e t}$ al., 1995; VIDOTTO et al., 1997, 1998).

Nos EUA, a anaplasmose é responsável pela morte de 50.000 a 100.000 cabeças de bovinos anualmente, com perdas estimadas em U\$ $300 \mathrm{mi}-$ lhões. Ela atinge cerca de $30 \%$ das regiões enzoóticas do Estado do Texas, provocando a morte em $36 \%$ dos casos clínicos, $24 \%$ de abortos, perda de peso médio de $86 \mathrm{~kg}$ por animal, durante a fase aguda da infecção e aumento de U\$ 52 e U\$ 30 com serviços veterinários e manejo, respectivamente (PALMER et $\boldsymbol{a l} .$, 1986).

O A. marginale é transmitido biológica e mecanicamente por um grupo diversificado de artrópodes (KREIER et al., 1991). O carrapato Boophilus microplus é o principal transmissor de $\boldsymbol{A}$. marginale no Brasil (MARTINS \& CORRÊA, 1995) pelas vias transestadial e mecânica, sendo que a via transovariana ainda está sendo avaliada (CONNEL \& HALL, 1972; RIBEIRO et al., 1995). Insetos hematófagos (moscas, mosquitos, tabanídeos) e agulhas de injeção também contribuem para a transmissão da doença (GUGLIELMONE, 1994; SOLARI \& QUINTANA, 1994; FARIAS, 1995). A forma congênita de transmissão em bovinos pode ocorrer (ZAUGG, 1985; RIBEIRO $\boldsymbol{e t}$ al., 1995; ANDRADE, 1998), ocasionando a anaplasmose neonatal (NORTON et al., 1983).

A imunidade conferida contra $\boldsymbol{A}$. marginale é de duração variável e de origem humoral e celular. $\mathrm{Na}$ anaplasmose, há uma evidência de resposta auto-imune durante a fase aguda, parcialmente responsável pela anemia (CARSON \& BUENING, 1979), na qual o baço tem importante função no desenvolvimento e manutenção da imunidade, pois os eritrócitos são rapidamente removidos da circulação, sem evidência de hemólise intravascular. A esplenectomia prejudica a formação de imunoglobulinas M (IgM), especialmente na resposta primária, envolvendo a síntese de anticorpos. As IgM aparecem no início da resposta imunológica e são anticorpos fixadores de complemento e aglutinantes, sendo responsáveis por $75 \%$ da atividade de fixação de complemento, enquanto as Imunoglobulinas $\mathrm{G}$ ( $\mathrm{IgG}$ ) aparecem mais tarde persistindo por vários meses (KLAUS \& JONES, 1968). Os bezerros que se infectam nos primeiros dias de vida, em regiões onde o carrapato está presente durante o ano todo, apresentam maior resistência devido à absorção de anticorpos colostrais, imunidade celular e presença de fatores séricos de resistência (MADRUGA et al., 1987a).

As linfocinas, especialmente os interferons, com alguma atividade semelhante ao fator de inibição de migração (MIF), são importantes na resposta imune do hospedeiro e, possivelmente, estão envolvidas na ativação dos macrófagos e ou linfócitos $\mathrm{T}$, incluindo funções helper (PALMER, 1989).

A opsonização de corpúsculos iniciais de A. marginale pelo anticorpo produzido em animais imunizados com a proteína majoritária de superfície (MSP1) resultou em aumento da fagocitose quando comparado com animais imunizados com ovoalbumina. Esse mecanismo pode desempenhar um importante papel na proteção in vivo de animais desafiados. A fagocitose, como um mecanismo chave de imunidade, poderia ser afetada por dois fatores, esplenectomia e supressão da função linfocítica em bovinos desafiados. Assim, a otimização de imunidade protetora pode requerer estímulos apropriados de anticorpos opsonizantes e também aumento da função de macrófagos (CANTOR et al., 1993).

Proteínas majoritárias de superfície de $\boldsymbol{A}$. marginale (MSPs) desempenham importante papel no desenvolvimento da resposta imune de animais infectados (PALMER \& McGUIRE, 1984). As MSPs foram reconhecidas por anticorpos policlonais e designadas MSP1a (105kDa), MSP1b (100kDa), MSP2 (36kDa), MSP3 (86kDa), MSP4 (31kDa) e MSP5 $(19 \mathrm{kDa})$. Estas proteínas estão presentes em cepas de diferentes regiões do mundo (VIDOTTO et al., 1994; PATARROYO et al., 1994; ANDRADE, 1998). A imunização de bovinos com as MSPs nativas e recombinantes de $\boldsymbol{A}$. marginale induziu proteção significativa contra anaplasmose aguda (PALMER et al. 1986, 1988; PALMER, 1989). Estas duas proteínas recombinantes (MSP3 e MSP5) mostraram potencial para uso em testes de diagnóstico (McGUIRE et al., 1991; NDUNG'U et al. 1995).

O A. marginale determina as formas clínicas aguda, superaguda, leve e/ou crônica, (RISTIC, 1981; MARTINS \& CORRÊA, 1995), com um período pré-patente de 20 a 40 dias seguido por parasitemia. No pico da enfermidade, a queda do hematócrito é acentuada e mais de $75 \%$ dos eritrócitos podem estar infectados, com o quadro podendo persistir por uma a duas semanas (NASCIMENTO et al., 1981; KREIER et al., 1991). Os sinais observados consistem de anemia hemolítica, icterícia, dispnéia, taquicardia, febre, fadiga, lacrimejamento, sialorréia, diarréia, micção freqüente, anorexia, perda de peso, aborto, às vezes agressividade (RISTIC, 1981; ALDERINK \& DIETRICH, 1983; BARBET, 1995), podendo levar o animal à morte em menos de 24 horas (FARIAS, 1995).

Existem três situações que devem ser observadas para a implantação de um controle racional: áreas livres de doenças transmitidas por carrapato, 
onde a população bovina é susceptível às doenças; áreas de instabilidade enzoótica, em que as condições climáticas não são totalmente favoráveis ao desenvolvimento do carrapato, porém, possibilitam a ocorrência de infestações temporárias em população de risco; áreas de estabilidade enzoótica, onde as condições climáticas são favoráveis ao desenvolvimento dos vetores, sendo que os prejuízos causados pelo carrapato em si são mais importantes que aqueles causados pelos agentes que transmitem (ARTECHE, 1992).

Diversas formas de controle têm sido empregadas como medidas higiênico-sanitárias (fômites, controle de moscas e outros insetos), administração de medicamentos (oxitetraciclina ou clortetraciclina, controle de carrapatos, avaliação da resistência aos carrapaticidas), vacinas e avaliação dos níveis de anticorpos, através de uma variedade de testes sorológicos capazes de avaliarem o grau de imunidade dos rebanhos, considerando-se os custos e a zona de ocorrência desta rickettsiose.

\section{DIAGNÓSTICO}

Os sinais clínicos da anaplasmose, evidentes em animais susceptíveis, não são específicos, sendo necessário o diagnóstico diferencial de outras enfermidades. A literatura mostra uma grande variedade de testes laboratoriais que podem ser utilizados para a pesquisa direta do A. marginale e seus componentes, ou antígenos e anticorpos, que podem estar presentes nos humores de animais acometidos pela infecção. O diagnóstico anátomo-patológico é efetuado através de necropsia, para observação das alterações presentes no animal. As alterações macroscópicas mais observadas são sangue fino e aquoso, mucosas e serosas anêmicas ou ictéricas, hepatoesplenomegalia, rins aumentados e escuros, vesícula biliar distendida com bile densa, grumosa e congestão cerebral. Os sinais são bastante variáveis, dependendo da cepa do agente e susceptibilidade do hospedeiro, necessitando de um diagnóstico laboratorial mais detalhado, para identificação da rickettsia e pesquisa de anticorpos conta A. marginale (FAO, 1993; FARIAS, 1995).

O diagnóstico laboratorial da anaplasmose emprega métodos diretos e indiretos, em que a escolha da prova está relacionada com facilidade de execução e ou dos reagentes, da infra-estrutura e capacidade técnica de cada laboratório.

\section{Diagnóstico Direto}

$\mathrm{Na}$ fase aguda da doença, quando a parasitemia é alta, Anaplasma spp é facilmente detectados nos eritrócitos de bovinos, através de esfregaços sangüíneos delgados corados pelo Método Giemsa (FAO, 1993; FARIAS, 1995). Esfregaços de fragmento de sangue coagulado também podem ser utilizados para a confecção de lâminas (STOBBE $\boldsymbol{e t}$ al., 1993). Entretanto, quando os animais se recuperam, tornando-se portadores, com baixa parasitemia, a visualização do parasito, por esse método, torna-se extremamente difícil e falha. Nesse sentido, técnicas como, sondas de DNA, PCR e outros métodos para detecção direta de antígenos, com altas sensibilidade e especificidade, têm sido desenvolvidos para detecção do Anaplasma spp e ou de seus componentes. (FARIAS, 1995; BÖSE et al., 1995).

$\mathrm{O}$ isoteste consiste de subinoculações do sangue de animal portador em animal receptor susceptível e esplenectomizado e também pode ser utilizado para identificar infecções latentes por $\boldsymbol{A}$. marginale. $\mathrm{O}$ método foi mais utilizado no passado, permitindo uma identificação segura de animais com infecções inaparentes com baixas parasitemias. Porém, devido aos altos custos, tempo prolongado de realização e necessidade de animais experimentais, o cultivo celular tem se apresentado como método alternativo, apresentando-se tão sensível quanto o isoteste (FAO, 1993; BÖSE et al., 1995). Entretanto, as subinoculações ainda têm sido empregadas em trabalhos experimentais, quando são necessários animais seguramente negativos para se verificar especificidade de teste de imunodiagnóstico (KNOWLES et al. 1996).

TRUEBLOOD et al. (1991) desenvolveram um teste imunoenzimático para captura de antígeno (ELISA de captura), utilizando anticorpos monoclonais específicos para reconhecer proteínas de superfície de A. marginale em cepas antigenicamente distintas, sendo capaz de detectar $1,1( \pm 0,5)$ $\%$ de eritrócitos parasitados, permitindo a detecção da infecção, em média 2,5 dias, antes de aparecerem os sinais clínicos da doença.

Sondas, contendo fragmentos de genes que codificam antígenos de superfície de $\boldsymbol{A}$. marginale, foram desenvolvidas para a detecção de DNA dessa rickettsia em eritrócitos de bovinos e carrapatos infectados (GOFF $\boldsymbol{e t}$ al., 1988; ABOYTESTORRES \& BUENING, 1990). As sondas podem ser utilizadas para determinar infecção de várias espécies de carrapatos frente a diferentes isolados de A. marginale, prevalência e incidência de carrapatos infectados em áreas enzoóticas, relação entre carrapatos infectados e surtos da doença (GOFF et al., 1988). Sondas de RNA foram desenvolvidas para detecção e quantificação de baixos níveis de parasitemia, indetectáveis microscopicamente, identificando portadores crônicos de anaplamose. É uma prova específica, capaz de detectar até 0,01ng de DNA 
genômico, 500 a 1.000 eritrócitos infectados em $0,5 \mathrm{ml}$ de sangue, o que equivale a uma parasitemia de $0,000025 \%$ capaz de permitir a infecção para o carrapato, sendo 4.000 x mais sensível que a identificação por microscópio óptico (ERIKS et al., 1993).

A PCR é uma técnica para amplificação in vitro de seqüência específica de DNA, altamente sensível, desenvolvida para detectar pequenas quantidades de DNA de diferentes agentes em amostras de sangue ou tecidos. Pode ser empregada na pesquisa de hemoparasitas em bovinos e em artrópodes nos diversos estádios de desenvolvimento (STICH $\boldsymbol{e t}$ al., 1993). A técnica da PCR amplifica repetidamente uma seqüência específica de DNA do genoma do organismo alvo, produzindo um produto facilmente detectável. A sensibilidade analítica do teste da PCR múltipla, avaliada por hibridação de ácido nucléico com sonda não radioativa, foi de $0,0001 \%$ de eritrócitos infectados, em fragmentos de DNA especificamente amplificados, de amostra contendo DNA de A. marginale, por Southern blotting (FIGUEROA et al., 1993; BÖSE et al., 1995). Devido à alta sensibilidade e especificidade da técnica da PCR, ela é utilizada para validar outras técnicas de diagnóstico e expedição de certificado para exportação de animais (BÖSE et al., 1995).

Uma modificação da técnica da PCR foi descrita por JACKSON et al. (1994), com a introdução de uma segunda reação de amplificação do DNA, a partir do produto da primeira reação, utilizando "primers internos", denominando-a de nestedPCR (nPCR). Essa técnica utiliza, portanto, duas PCRs consecutivas, melhorando, desse modo a sensibilidade da técnica original. Uma nPCR, descrita por TORIONI de ECHAIDE et al. (1998), demonstrou ser capaz de detectar 30 eritrócitos infectados por ml de sangue, o que corresponde a um aumento de 10 a 100 vezes na sensibilidade com relação ao teste da PCR, sonda de RNA e hibridização descritas por ERIKS et al., 1989 e GE et al. 1995.

\section{Diagnóstico Indireto}

O diagnóstico indireto utilizado para pesquisa de anticorpos contra $\boldsymbol{A}$. marginale é empregado em levantamentos epidemiológicos, possibilitando conhecer a porcentagem de animais portadores, o grau de proteção do rebanho, a faixa etária mais afetada, dados esses necessários para estabelecimento de programas de controle dessa rickettsiose (KLAUS \& JONES, 1968).

As provas de aglutinação apresentam como princípio básico a reação de anticorpos bivalentes e antígenos polivalentes, com formação de compostos macromoleculares visíveis. As variações dessas provas incluem aglutinação em tubo capilar, aglutinação rápida e conglutinação rápida. Na prova de aglutinação em tubo capilar, a reação positiva é identificada pela formação de grumos suspensos, irregularmente distribuídos no tubo capilar (RISTIC, 1962; VEGA y MURGUIA, 1993). A prova de aglutinação rápida (AMERAULT \& ROBY, 1968) foi utilizada, inicialmente, como prova de campo, e mais tarde incluído o fator sérico bovino (KUTTLER, 1975) para controlar as reações falsonegativas, contribuindo para aumentar a sensibilidade no diagnóstico de anticorpos contra A. marginale. $\mathrm{O}$ fator sérico bovino fornece o complemento e a conglutinina, proteína existente no soro de ruminantes, os quais são responsáveis pela reação de conglutinação (ROSE et al., 1978). Assim, o teste passou a ser chamado teste de conglutinação rápida (TCR) ou teste do cartão, com utilização em levantamentos epidemiológicos (MADRUGA et al., 1987b)

O teste de aglutinação pelo látex consiste na aglutinação de anticorpos contra $\boldsymbol{A}$. marginale com partículas de látex sensibilizadas com frações solúveis de antígenos. Estudos recentes têm utilizado antígenos de $\boldsymbol{A}$. marginale produzido em cultivo de células de Ixodes scapularis para se evitar a contaminação com estromas de eritrócitos, freqüente em outros testes. É um teste rápido, semi-automático, no qual reagem o soro diluído com as proteínas de $\boldsymbol{A}$. marginale ligadas a microesferas de látex. As microesferas de látex sensibilizadas aglutinam na presença de anticorpos contra o A. marginale, determinando variação na transmitância da luz. Seus resultados são compatíveis com o teste de fixação de complemento (RODGERS et al., 1997).

O teste de hemaglutinação é baseado na aglutinação de eritrócitos normais de ovino e bovino sensibilizados com antígenos ou anticorpos (CARSON \& BUENING, 1979), sendo capaz de detectar anticorpos em baixas concentração (ROITT et al., 1989).

A prova de fixação de complemento $(\mathrm{CF})$ é baseada em reações de anticorpos IgM, produzidos no início da infecção primária, com sensibilidade menor em animais com infecções crônicas por $\boldsymbol{A}$. marginale (BÖSE et al., 1995). A prova utiliza antígenos produzidos a partir de eritrócitos infectados, apresentando boa correlação com a prova de aglutinação em tubo e sensibilidade de 95 a $96 \%$. Os reagentes empregados, complemento, sistema hemolítico e antígeno, são titulados como o soro, avaliando o grau de hemólise (KUTTLER, 1975), com diferenças nos títulos em isolados de cepas de $\boldsymbol{A}$. marginale (KUTTLER et al., 1984).

No teste de imunofluorescência indireta (IFI), são utilizados como antígenos esfregaços san- 
güíneos com eritrócitos parasitados (MADRUGA et al., 1986). Os anticorpos $\mathrm{IgG}$, presentes no soro teste, reagem com o antígeno, sendo identificados por anticorpos anti-IgG bovina marcados com isotiocianato de fluoresceína (conjugado). Esse teste apresenta boa sensibilidade, mas diferentes níveis de fluorescência, fluorescência inespecífica, rastros de pontos irregulares, fadiga e subjetividade do operador, são alguns inconvenientes apresentados pelo teste, que têm dificultado a sua padronização (GOFF et al., 1985; BÖSE et al., 1995).

O teste imunoenzimático de ELISA é capaz de detectar e quantificar a presença de anticorpos em baixas concentrações. O antígeno solúvel purificado, produzido a partir de amostras de sangue com $80 \%$ de parasitemia de $\boldsymbol{A}$. marginale, é adsorvido pela placa de poliestireno (DUZGUN et al. 1988; MADRUGA et al., 1996). Numa primeira etapa da reação, os anticorpos específicos presentes no soro a ser testado reconhecem o antígeno aderido à placa. Na etapa seguinte, adiciona-se o conjugado, constituído por anticorpos anti-IgG bovina marcados com uma enzima, por exemplo a peroxidase ou fosfatase alcalina, que se liga ao complexo antígenoanticorpo. A enzima presente no conjugado degrada o substrato resultando numa reação colorimétrica. Essa reação pode ser quantificada através da leitura da densidade óptica obtida por espectrofotômetro (BARRY et al., 1986; NAKAMURA et al., 1988; NIELSEN et al., 1996). A intensidade da cor determina a concentração do anticorpo presente no soro testado, assim, quanto mais anticorpos estiverem presentes no soro, maior será a intensidade da cor. No soro negativo não ocorre ligação entre o anticorpo e o antígeno e o teste mantém-se incolor (TIZARD, 1992; FARIAS, 1995). É uma prova sensível e específica, podendo ser automatizada, permitindo o processamento de um grande número de amostras (BÖSE et al., 1995).

O teste de ELISA por competição (cELISA) utiliza como antígeno a proteína recombinante de $19 \mathrm{kDa}$ do A. marginale (MSP5), presente em Anaplasma spp (KNOWLES $\boldsymbol{e}$ al., 1995). A MSP5 no teste é reconhecida por anticorpo monoclonal ANAF16C1, apresentando especificidade dependente do anticorpo monoclonal usado. Os soros positivos são aqueles que apresentam taxa de inibição inferior a 75\% (KNOWLES et $\boldsymbol{a l} ., 1996)$, nos quais os anticorpos do soro teste e o anticorpo monoclonal competem pelos mesmos epitopos presentes no antígeno recombinante (BÖSE et al., 1995).

A reação imunoenzimática do ELISA é utilizada para detecção rápida de antígeno ou anticorpo. Utiliza pequena quantidade de reagente depositado em um ponto sobre discos de nitrocelulose com afinidade por proteína, havendo formação de cor após a reação anticorpo antígeno-específico e antianticorpo ligado à enzima e pela adição de um substrato cromogênico precipitável, facilmente visualizado. O teste pode ser empregado na titulação e triagem de soros, com sensibilidade semelhante a imunofluorescência indireta (PAPPAS, 1988; MONTENEGRO-JAMES et al., 1990).

O "Western Blot" é um teste utilizado para reconhecimento de antígenos específicos marcados que são revelados por anti-soro marcado. A eletroforese em gel de poliacrilamida separa as proteínas em bandas, através de corrente elétrica, que posteriormente são transferidos do gel para membranas de nitrocelulose. As bandas reveladas são fotografadas e identificadas de acordo com seus pesos moleculares enquadrando-se em três categorias, alta (H-91 a $108 \mathrm{kDa})$, média $(\mathrm{M}-35$ a $47 \mathrm{kDa})$ e baixa (L-15 a $27 \mathrm{kDa})$. O teste pode detectar a infecção por A. marginale em poucos dias após a exposição ao agente, podendo ser empregado em casos de surto e portadores inaparentes (KWAK \& SMITH, 1989).

\section{CONCLUSÕES}

Nas últimas décadas, o diagnóstico laboratorial da Anaplasmose evoluiu consideravelmente, proporcionando aos laboratórios uma variedade de testes, desde os mais simples (Giemsa, testes de aglutinação e fixação do complemento) até os mais sofisticados (cELISA, "Western blot" e PCR). Essas novas metodologias, com maiores sensibilidade e especificidade, têm contribuído significativamente para a realização de estudos mais avançados sobre a epidemiologia da doença, permitindo a adoção de medidas profiláticas mais eficazes.

\section{REFERÊNCIAS BIBLIOGRÁFICAS}

ABOYTES-TORRES, R., BUENING, G.M. Development of a recombinant Anaplasma marginale DNA probe. Vet Microbiol, v.24, p.391-408, 1990.

ALDERINK, F.J., DIETRICH, R.A. Economic and epidemilogical implications of anaplasmosis in Texas beef cattle herds. The Texas A\&M University System, Texas, B1426, p.1-16, 1983.

AMERAULT, T.E., ROBY, T.O. A rapid card test agglutination for bovine anaplasmosis. J Am Vet Med Assoc v.153, n.12, p.1828-1834, 1968.

ANDRADE, G. M. Estudo sobre a prevalência e infecção natural por Anaplasma marginale em bovino da raça holandesa na região de Londrina - Pr. Londrina, 1998. 38p. Dissertação (Mestrado em Sanidade Animal) - Curso de Mestrado em Sanidade Animal, Universidade Estadual de Londrina, 1998.

Ciência Rural, v. 31, n. 2, 2001. 
ARTECHE, C.C.P. Imunoprofilaxia da tristeza parasitária bovina (TPB) no Brasil. Uso de cepas atenuadas da Babesia spp e de cepa de Anaplasma. A Hora Veterinária, ano 11, n.66, mar/abr, p.39-42, 1992.

ARTILES, J., ALVES-BRANCO, F. de P.J., MARTINS, J.R., et al. Prevalência de Babesia bovis, Babesia bigemina e Anaplasma marginale no município de Bagé, RS. Rev Bras Parasitol Vet, v.4, n.2, supl.2, p.179, 1995. (Resumo).

BARBET, A.F. Recent developments in molecular biology of anaplasmosis. Vet Parasitol., v.57, p.57, 43-49, 1995.

BARRY, D.N., PARKER, R.J., DE VOS, A.J., et al. A microplate enzyme-linked immunosorbent assay for measuring antibody to Anaplasma marginale in cattle serum. Aust Vet J, v.63, n.3, p.76-79, 1986

BAUMGARTNER, W., SCHLERKA, G., FUMICZ, M, et al. Seroprevalence survey for Anaplasma marginale-infection of Austrian cattle. J Vet Med Med, v.39, n.2, p.97-104, 1992

BÖSE, R., JORGENSEN, W.K., DALGLIESH, R.J., $\boldsymbol{e}$ t al. Current state and future trends in the diagnosis of babesiosis. Vet Pasasitol, n.57, p.61-74, 1995.

CANTOR, G.H., PONTZER, C.H., PALMER, G.H. Opsonization of Anaplasma marginale mediated by bovine against surface protein MSP-1. Vet Immunol Immunopathol, v.37, p.343-350, 1993

CARSON, C.A., BUENING, G.M. The immune response of cattle to live and inactivated Anaplasma vacines and response challenge. S Afr Vet Assoc, v.38, n.4, p.330-331, 1979.

CONNEL, M., HALL, W.T.K. Transmission of Anaplasma marginale by the cattle tick Boophilus microplus. Aust Vet J, v.48, p.177, 1972 .

DALGLIESH, R.J., JORGENSEN, W.K., de VOS, J. Australian frozen vaccines for the control of babesiosis and anaplasmosis in cattle - review. Trop Anim Hlth Prod, v.22, p.44-52, 1990.

DUZGUN, A., SCHUNTNER, C.A., WRIGHT, IG., et $\boldsymbol{a l}$. A sensitive ELISA technique for the diagnosis of Anaplasma marginale infections. Vet Parasitol, v.29, p.1-7, 1988.

ERIKS, I.S., PALMER, G.H., McGUIRE, T.C., et al. Detection and quantitation of Anaplasma marginale in carrier cattle by using a nucleic acid probe. J Clin Microbiol, v.27, n.2, p.279-284, 1989.

ERIKS, I.S., STILLER, D., PALMER, G.H., et al. Impact of persistent Anaplasma marginale Rickettsemia on Tick infection and Transmiss. J Clin Microbiol v.31, n.8, p.2091-2096, 1993.

FAO - Organizaçion de las Naciones Unidas para la Agricultura y la Alimentacion. Consulta de Expertos. Merida, México Informe FAO, Out, 1993. 27p.

FARIAS, N.A. da R. Diagnóstico e controle da tristeza parasitária bovina. Guaíba, Porto Alegre : Agropecuária, 1995. $80 \mathrm{p}$

FIGUEROA, J.V., CHIEVES, L.P., JOHNSON, G.S., et al. Multiplex polymerase chain reaction based assay for the detection of Babesia bigemina, Babesia bovis e Anaplasma marginale DNA in bovine blood. Vet Parasitol, v.50, p.69-
81,1993

GE, N.L., KOCAN, K.M., MURPHY, G.L. et al. Detection of Anaplasma marginale DNA in bovines erythrocytes by slotblot and in situ hybridization with a PCR-mediated digoxigeninlabeled DNA probe. J Vet Diagn Invest, v.7, p.465-472, 1995.

GOFF, W.L., JOHNSON, W.C., KUTTLER, K.L. Development of an indirect fluorescence antibody test, using microfluorometry as a diagnostic test for bovine anaplasmosis. Am J Vet Res, v.46, n.5, p.1080-1084, 1985.

GOFF, W., BARBET, A., STILLER, D., et al. Detection of Anaplasma marginale-infected tick vectors by using a cloned DNA probe. Proc Natl Acad Sci, v.85, p.919-923, 1988.

GUGLIELMONE, A. Epidemiologia y prevencion de los Hemoparasitos (Babesia y Anaplasma) en la Argentina. In: NARI, A., FIEL, C. Enfermidades parasitarias de importancia econômica en bovinos. Montevideo, Uruguay : Hemisferio Sur, 1994. Cap.23, p.460-479.

JACKSON, D.P., HAIDEN, J.D., QUIRKE, P. Extraction of nucleic acid from fresh and archival material. In: MCPHERSON, M.J., QUIRKE, P., TAYLOR, G.R. PCR A practical approach. New York: IRP, 1994. v.1, p.29-50.

JAMES, M.A., CORONADO, A., LOPEZ, W., et al. Seroepidemiology of bovine anaplasmosis and babesiosis in Venezuela. Trop Anim Hith Prod, v.17, p.9-18, 1985.

JONGEJAN, F., PERRY, B.D., MOORHOUSE, P.D.S., $\boldsymbol{e} \boldsymbol{t}$ al . Epidemiology of bovine babesiosis and anaplasmosis in Zambia. Trop Anim Hlth Prod, v.24, n.1, p.9-14, 1988.

JORGENSEN, W.K., WEILGAMA, D.J., NAVARATNE, M., $\boldsymbol{e}$ al. Prevalence of Babesia bovis and Anaplasma marginale at selected localities in Sri Lanka. Trop Anim Hith Prod, v.24, p.9-18, 1992.

KLAUS, G.G.B., JONES, E.W. The immunoglobulin response in intact and splenectomized calves infected with Anaplasma marginale. J Immunol, v.100, n.5, p.991- 999, 1968.

KNOWLES, D.P., PERRYMAN, L.E., McELWAIN, T.F., $\boldsymbol{e}$ t al. Conserved recombinant antigens of Anaplasma marginale and Babesia equi for serologic diagnosis. Vet Parasitol, v.57, p.93-96, 1995.

KNOWLES, D.P., TORIONI de ECHAIDE, S., PALMER, G., $\boldsymbol{e}$ al. Antibody against an Anaplasma marginale MSP5 epitope common to tick and erythrocyte stages identifies persistently infected cattle. J Clin Microbiol, v.34, n.9, p.2225-2230, Sep.1996.

KREIER, J.P., GOTHE, R., IHLER, G.M., et al. The hemotrophic bacteria: The Families Bartonellaceae and Anaplasmataceae. In: BALOWS, A., TRUPER, H.G., DOWORKIN, M., et al. The Prokaryotes: A handbook on the biology of bacteria: ecophysioology, isolation, identification, applications. 2. ed. New York : SpringVerlag, 1991. Cap.225, p.3994-4022.

KUTTLER, K.L. Una revision sobre el diagnóstico de anaplasmosis. In: REUNION DE DISCUSION SOBRE HEMOPARÁSITOS (ANAPLASMOSIS Y BABESIOSIS). Centro Internacional de Agricultura Tropical, 1975, Cali, Colombia. Anais... Colombia : Centro Internacional de Agricultura Tropical, 1975. 137p. p.97-107. 
KUTTLER, K.L., ZAUGG, J.L., JOHNSON, L.W. Serologic and clinical responses of premunized, vaccinated, and previously infected cattle to challenge exposure by two different Anaplasma marginale isolates. Am J Vet Res, v.45, n.11, p.2223-2226, 1984.

KWAK, Y.R., SMITH, R.D. Evaluation of the diagnostic performance of Anaplasma marginale antigens identified by Western Blotting. Proc of Eight Nat Vet Hemop Disease, Conf. St. Louis, MO, 1989. p.281-288.

.MADRUGA, C.R., KESSLER, R.H., SACCO, A.M.S., et al. Produção de antígenos e análise preliminar do teste de imunofluorescência indireta para diagnóstico de anticorpos contra Anaplasma marginale. Campo Grande, MS : Centro Nacional de Pesquisa de Gado de Corte (EMBRAPA-CNPGC), 1986. p.1-4. (Pesquisa em andamento, 31).

MADRUGA, C.R., HORNER, M.R., SCHENK, M.A.M., et al. Avaliação preliminar de parâmetros epidemilógicos da tristeza parasitária bovina no Estado de Mato Grosso do Sul. Campo Grande, MS : Centro Nacional de Pesquisa de Gado de Corte (EMBRAPA-CNPGC), $1987^{\mathrm{a}}$ p.1-7. (Pesquisa em andamento, 38).

MADRUGA, C.R., KESSLER, R.H., MIGUITA, C.T., et al. Avaliação preliminar do teste de aglutinação rápida para diagnóstico de anticorpos contra Babesia bigemina. Campo Grande, MS : Centro Nacional de Pesquisa de Gado de Corte (EMBRAPA-CNPGC), 1987b. p.1-6. (Pesquisa em andamento, 37).

MADRUGA, C.R., HONER, M.R., ANDREOTTI, R., et al. Prevalência de Anaplasma marginale em três regiões do estado da Paraíba. In: CONGRESSO INTERNACIONAL DE MEDICINA VETERINÁRIA EM LÍNGUA PORTUGUESA, 6, 1994, Salvador, BA. Anais... Bahia : Escola de Medicina Veterinária da Universidade Federal da Bahia, 1994. p.350-352.

MADRUGA, C.R., MARQUES, A.P.C., MIGUITA, M. et al. A prelyminary evaluation of an enzyme linked immunosorbent assay (ELISA) for detection of antibodies against Anaplasma marginale. In: CONGRESSO PANAMERICANO DE CIÊNCIAS VETERINÁRIAS, 15, 1996, Campo Grande. MS. Anais... Campo Grande : Colégio Brasileiro de Parasitologia Veterinária, MS, 1996. 458p. p. 297

MARTINS, J.R., CORRÊA, B.L. Babesiose e anaplasmose bovina: aspectos destas enfermidades. Pesquisa Agropecuária Gaúcha, Porto Alegre, v.1, n.1, p.51-58, 1995.

McGUIRE, T.C., DAVIS, W.C., BRASSFIELD, A.L. et al. Identification of Anaplasma marginale long-term carrier cattle by detection of serum antibodies to isolated MSP3. J Clin Microbiol, v.29, n.4, p.788-793, 1991.

MONTENEGRO-JAMES, S., GUILLE, A.T., TAPANG, P., et al. Use of the dot enzyme-linked immunosorbent assay with isolated Anaplasma marginale initial bodies for serodiagnosis of anaplasmosis in cattle. Am J Vet Res, v.51, n. 10, p.1518-1521, 1990.

NAKAMURA, Y., SHIMIZU, S., MINAMI, T., et al. Enzymelinked immunosorbent assay using solubilised antigen for detection of antibodies to Anaplasma marginale. Trop Anim Hlth Prod, v.20, p.259-266, 1988.
NASCIMENTO, M.D. do, PINHEIRO, J.G., RIBEIRO, M.F.B. Alterações do quadro eritrocitário e sideremia de bezerros portadores de anaplasmose. Niterói, RJ : Empresa de Pesquisa Agropecuária do Estado do Rio de Janeiro, 1981. p.1-2. (Comunicado Técnico PESAGRO-RIO, 97).

NIELSEN, K., SMITH, P., GALL, D., et al. Development and validation of an indirect enzyme immunoassay for detection of antibody to Anaplasma marginale in bovine sera. Vet Parasitol, v.67, p.133-142, 1996.

NORTON, J.H., PARKER, R.J., FORBES-FAULKNER, J.C. Neonatal anaplasmosis in calf. Aust Vet J, v.16, n.11, p.348, 1983.

NDUNG'U, L.W., AGUIRRE, C., RURANGIRWA, F.R., $\boldsymbol{e}$ t al. Detection of Anaplasma ovis in infection in goats by major surface protein 5 competitive inhibition enzyme-linked immunosorbent assay. J Clin Microbiol, v.33, p.675-687, 1995.

OLIVEIRA, A.A. de, PEDREIRA, P.A.S., ALMEIDA, M.P.R.S de, et al. Doenças de bezerros. II. Epidemiologia da anaplasmose no estado de Sergipe. Arq Bras Med Vet Zoot., v.44, n.5, p.377-386, 1992.

PALMER, G.H., McGUIRE, T.C. Immune serum against Anaplasma marginale initial bodies neutralizes infectivity for cattle. J Immunol, v.133, p.1010-1015, 1984.

PALMER, G.H., BARBET, A.F., DAVIS, W.C., $\boldsymbol{e} \boldsymbol{t} \boldsymbol{a l}$. Immunization with an isolate-common surface protein protects cattle agaisnt anaplasmosis. Science, v.231, p.12991302,1986

PALMER, G.H. OBERLE, S.M., BARBET, A.F., $\boldsymbol{e}$ t al Immunization with a 36 kildalton surface protein induces protection against homologous and heterologous Anaplasma marginale challenge. Infect Immun, v.56, p.1526-1531, 1988.

PALMER, G.H. Anaplasma vaccines. In: WRIGHT, I.G. Veterinary protozoan and hemoparasite vacines. Boca Raton, Flórida : CR, 1989. Cap.1, p.1-29.

PAPPAS, M.G. Recent applications of the Dot-ELISA in immunoparasitology. Vet Parasitol, n.29, p.105-129, 1988.

PATTARROYO, J.H., VILLA, O., DIAZGRANADOS, H Epidemiology of cattle anaplasmosis in Colombia. I. Prevalence and distribution of agglutinating antibodies. Trop Anim Hlth Prod, v.10, p.171-174, 1978.

PATARROYO, J.H., HENCKEL, D.J., PRATES, A.A., $\boldsymbol{e} \boldsymbol{t}$ al. Antigenic profile of a pure isolate of Anaplasma marginale of Brazilian origen, using a Western blot technique. Vet Parasitol, v.52, p.129-137, 1994.

RIBEIRO, M.F.B., REIS, R. Prevalência da anaplasmose em quatro regiões do estado de Minas Gerais. Arq Esc Vet UFMG, v.33, n.1. p.57-62, 1981.

RIBEIRO, M.F.B., LIMA, J.D., GUIMARÃES, A.M., $\boldsymbol{e} \boldsymbol{t} \boldsymbol{a l}$. Transmissão congênita de anaplasmose bovina. Arq Bras de Med Vet e Zoot, n.47, v.3, p.297-304, 1995.

RISTIC, M. A capillary tube-agglutination test for anaplasmosis - a preliminary report. J Am Vet Med Assoc, v.141, n.5, p.588-594, 1962. 
RISTIC, M., KREIER, J.P. Family Anaplasmataceae. In: BUCHANAN, R.E., GIBBONS, N.E. Bergey's Manual of Determinative Bacteriology. 8. ed. Baltimore : Williams \& Wilkins, 1974. p.906-914.

RISTIC, M. Anaplasmosis. In: RISTIC, M., McINTYRE, I. Diseases of cattle in the tropics - economic and zoonotic relevance. Current topics in veterinary medicine and animal science. The Hague/Boston/London, 1981. V.6, p.327-344

RODGERS, S.J., SALIKI, J.T., BLOUIN, E.F., et al. The development of a semi-automated latex agglunatination test for the dectetion of antibodies to Anaplasma marginale using a cell culture-derived antigen. In: BIENNIAL MEETING SOCIETY FOR TROPICAL VETERINARY MEDICINE, 4 1997, Montepellier, França. Anais... França : Society for Tropical Veterinary Medicine, 1997. 70p. p.63.

ROITT, I.M., BROSTOFF, J., MALE, D.K. Imunologia. São Paulo : Manole, 1989. Cap.25.

ROSE, J.E., AMERAULT, T.E., ROBY, T.O., et al. Serum levels of conglutinin, complement, and immunoconglutinin in cattle infected with Anaplasma marginale. Am J Vet Res, v.39, n.5, p.791-793, 1978

SOLARI, M.A., QUINTANA, S. Epidemiologia y Prevencion de los Hemoparasitos (Babesia y Anaplasma) en el Uruguay. In: NARI, A.; FIEL, C. Enfermidades parasitarias de importancia econômica en bovinos. Montevideo, Uruguay : Hemisferio Sur, 1994, Cap.24, p.481-507.

STICH, R.W., BANTLE, J.A., KOCAN, K.M., et al. Detection of Anaplasma marginale (Rickettsiales: Anaplasmacetaceae) in hemolymph of Dermacentor andersoni (Acari: Ixodidae) with the Polymerase Chain Reaction. J Med Entomol, v.30, n.4, p.781-788, 1993

STOBBE, N.S., CHAPLIN, E.L., ARAÚJO, F.A.P., $\boldsymbol{e} \boldsymbol{t} \boldsymbol{a l}$. Utilização do esfregaço de coágulo sangüíneo para o diagnóstico de Babesia e Anaplasma em bovinos. Arq Bras Med Vet Zoot, v.45, n.4, p.369-374, 1993.
TIZARD, I.R. Veterinary immunology: an introduction. 4 ed. Philadelphia : Saunders, 1992. 498 p.

TORIONI DE ECHAIDE, S., KNOWLES, D.P., McGUIRE, T.C., et al. Detection of cattle naturally infected with Anaplasma marginale in region of endemicity by nested PCR and a competitive enzyme-linked immunoabsorbent assay using recombinant major surface protein 5. J Clin Microbiol, v.36, n.3, p.777-782, 1998.

TRUEBLOOD, E.S., McGUIRE, T.C., PALMER, G.H. Detection of Anaplasma marginale rickettsemia prior to onset of clinical signs by using an antigen capture enzymelinked immunosorbent assay. J Clin Microbiol, v.29, n.7, p.1542-1544, 1991.

VEGA Y MURGUIA, C.A. Red de cooperacion tecnica entre laboratorios de investigacion y diagnostico veterinário, acta de la mesa redonda del programa de hemoparasitos, Montevideo, Uruguay : Oficina Regional de la FAO para America Latina y el Caribe, 1993. RLAC/93/29 - GAN -45: Diagnostico serologico de la Babesiosis Bovina Anexo VI: 50 p. p. $34-50$

VIDOTTO, M.C., McGUIRRE, T.V.C., McELWAIN, T.F., et al Intermolecular relationships of major surface proteins of Anaplasma marginale. Infect Immun, n.62. n.7, p.29402946, 1994

VIDOTTO, O., ANDRADE, G.M., AMARAL, C.H.S., $\boldsymbol{e} \boldsymbol{t} \boldsymbol{a}$. Frequência de anticorpos contra Babesia bigemina, B. bovis e Anaplasma marginale em rebanhos de bovinos leiteiros da região de Londrina, PR. Arq Bras Med Vet, v.49, n.5, p.659-665, 1997.

VIDOTTO, M.C., VIDOTTO, O., ANDRADE, G.M., $\boldsymbol{e} \boldsymbol{t} \boldsymbol{a l}$. Seroprevalence of Anaplasma marginale on cattle in Parana State, Brasil, by major surface protein 5 competitive inhibition enzyme-linked immunosorbentassay. Ann N Y Acad Sc, v.849, p.424-426, 1998.

ZAUGG, J.L. Bovine anaplasmosis: transplacental transmission as it relates to stage of gestation. Am J Vet Res, v.46, n.3, p.570-572, Mar, 1985.

Ciência Rural, v. 31, n. 2, 2001. 